JOURNAL

OF TOURISM

AND ECONOMIC
Journal of Tourism and Economic Vol.3, No.2, 2020, Page 126-134

ISSN: 2622-4631 (print), ISSN: 2622-495X (online)

Email: jurnalapi@gmail.com

Website: http://jurnal.stieparapi.ac.id/index.php/JTEC

DOI: https://doi.org/10.36594/jtec.v3i2.97

\title{
PENGARUH STRES DAN LINGKUNGAN KERJA TERHADAP KINERJA YANG DIMEDIASI MOTIVASI KERJA KARYAWAN HOTEL MM UGM YOGYAKARTA
}

\author{
Rahmat Abdullah \\ Politeknik Perikanan Negeri Tual \\ rahmat.abd@polikant.ac.id
}

\begin{abstract}
This research was conducted at MMUGM Hotel Yogyakarta, aimed to analyze and explain the effect of job Stress and Work Environment on Employee Performance with motivation as mediate variable. This study uses quantitative descriptive method, data collected through questionnaires and interviews, population of 85 people also used as sample known as census sampling methode, data was tested and analyzed using multiple linear regression and path analysis. The result of data analyze shows that the work environment has a positive and significant effect on employee's motivation and performance, job stress does not have positive and significant effect to employee's motivation and performance, work motivation mediates the effect of work stress on employee performance and motivation does not mediate the effect of work environment on employee performance MMUGM Hotel Yogyakarta.
\end{abstract}

Keywords : Job Stress, Work Environment, Work Motivation, Employee Performance 


\begin{abstract}
ABSTRAK
Penelitian ini dilakukan di Hotel MMUGM Yogyakarta, bertujuan untuk menganalisis dan menjelaskan Pengaruh Stres Kerja dan Lingkungan Kerja terhadap Kinerja Karyawan dengan di Mediasi oleh Motivasi. Penelitian ini menggunakan metode deskriptif kuantitatif, data dikumpulkan melalui penyebaran kuesioner dan wawancara, dengan populasi sebanyak 85 orang, sensus dipakai sebagai teknik pengambilan sempel, data diuji serta di analisis menggunakan regresi linear berganda dengan analisis jalur (path Analysis). Hasil analisis data menunjukan bahwa lingkungan kerja berpengaruh positif dan signifikan terhadap motivasi dan kinerja karyawan, stress kerja tidak berpengaruh positif dan signifikan terhadap motivasi dan kinerja karyawan, sementara berdasarkan hasil uji analisis jalur menunjukan bahwa, motivasi kerja memediasi pengaruh stress kerja terhadap kinerja karyawan, motivasi tidak memediasi pengaruh lingkungan kerja terhadap kinerja karyawan di Hotel MMUGM Yogyakarta.
\end{abstract}

Kata kunci : Stres Kerja, Lingkungan Kerja, Motivasi Kerja, Kinerja Karyawan 


\section{PENDAHULUAN}

Daerah Istimewa Yogyakarta (DIY) atau sering disebut 'Jogja', memiliki berbagai macam kegiatan wisata yang meliputi wisata alam, buatan, maupun budaya yang masing-masing memiliki daya tarik tersendiri, serta di dukung dengan berbagai macam sektor industri pariwisata seperti restoran, jasa pemandu wisata, transportasi dan akomodasi, menjadikan Jogja banyak dikunjungi oleh wisatawan nusantara (wisnus) maupun mancanegara (wisman). Hal itu terbukti dengan angka kunjungan yang terus meningkat setiap tahunnya.

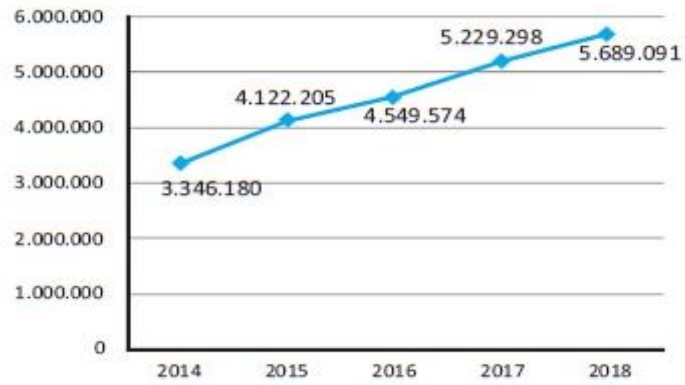

Gambar 1. Data Kunjungan Wisatawan Mancanegera dan Wisatwan Nusantara ke Yogyakarta Tahun 20142018

Sumber: Statistik Kepariwisataan Yogyakarta, 2018

Meningkatnya jumlah kunjungan wisatawan tersebut diatas kemudian ikut mempengaruhi tingkat hunian kamar hotel di Yogyakarta yang terdistribusi baik hotel berbintang, maupun non berbintang. Pada tahun 2014 tercatat ada 254.213 wisatawan mancanegara dan 3.091.967 wisatawan nusantara yang menginap pada hotel non berbintang maupun berbintang. Jumlah ini terus meingkat secara akumulasi, sampai pada tahun 2018 tercatat ada 416.374 wisatawan mancanegar dan 5.272.719 wisatawan nusantara yang menginap pada hotel non berbintang maupun hotel berbintang. (Statistik Kepariwisataan Yogyakarta, 2018).

Hotel MMUGM Yogyakarta merupakan hotel bintang tiga yang terletak di lingkungan akademis Universitas Gajah Mada. Pada awalnya hotel ini dikhususkan untuk kebutuhan internal kampus UGM, yaitu bagi mahasiswa S2 dan dosen-dosen tamu yang ingin menginap. Pada perkembangannya, karena permintaan pasar yang cukup tinggi akan akomodasi untuk tujuan wisata maupun bisnis, tahun 2006 manajemen Hotel MMUGM Yogyakarta memutuskan untuk menjadi perusahaan dengan profit oriented, karena tidak dapat dipungkiri dengan ceruk pasar wisatawan yang potensial menjadikan tingkat persaingan pada industri perhotelanpun semakin ketat (Yulianto, A. 2019).

Menghadapi persaingan bisnis yang semakin ketat saat ini, Hotel MMUGM Yogyakarta dituntut untuk selalu berinovasi dan memperhatikan serta memanfaatkan sumber daya yang mereka miliki agar dapat memenangkan persaingan usaha. Salah satu yang menentukan keberhasilan suatu usaha yaitu sumber daya manusia (SDM) yang dimiliki perusahaan. Mengingat kedudukan karyawan dalam suatu perusahaan sangat penting, maka karyawan diharapkan dapat memberikan kontribusi sehingga tujuan perusahaan akan tercapai (Setyawan, 2018), maka diperlukan adanya manajemen sumber daya manusia (MSDM) yang baik dalam mengelolah perusahaan agar produktif, efektif, dan efisien.

Mewujudkan kinerja karyawan yang baik merupakan salah satu tujuan dari MSDM. Kinerja karyawan menurut Afandi, P. (2018), adalah hasil kerja yang dapat dicapai oleh seseorang atau kelompok orang dalam suatu perusahaan sesuai dengan wewenang dan tanggung jawab masingmasing dalam upaya pencapaian tujuan organisasi secara illegal, tidak melanggar hukum dan tidak bertentangan dengan moral dan etika. Kinerja karyawan yang baik di Hotel MMUGM Yogyakarta dapat dipengaruhi beberapa faktor antara lain stress kerja, lingkungan kerja, dan motivasi kerja. Stres kerja adalah suatu kondisi ketegangan yang menciptakan adanya ketidakseimbangan fisik dan psikis, yang mempengaruhi emosi, proses berpikir, dan kondisi seorang karyawan (Zainal et al, 2015). Stres kerja pada karyawan Hotel MMUGM Yogyakarta bisa berasal dari 
dalam maupun luar lingkungan kerja. Stres kerja yang berasal dari dalam lingkungan kerja di Hotel MMUGM Yogyakarta misalnya karena adanya banyaknya tamu yang menginap terutama pada saat periode peak season yaitu ketika musim lebaran, natal dan tahun baru maupun saat high season yaitu pada periode liburan sekolah maupun summer bagi tamu yang berasal dari Eropa, dan juga karena menghadapi tamu dengan berbagai karakteristik seperti pelupa, suka curiga, pemarah dan sebagainya. Penyebab stres kerja dari lingkungan eksternal karyawan Hotel MMUGM Yogyakarta bisa berasal dari masalah pribadi, keluarga dan sebagainya, sehingga manajemen organisasi dituntut jeli dalam menghadapi kondisi seperti ini.

Lingkungan kerja dalam organisasi juga harus diperhatikan oleh manajemen, menurut Nitisemito dalam Nuraini, $T$. (2013), linkungan kerja adalah segala sesuatu yang ada disekitar karyawan dan dapat mempengaruhi dalam menjalankan tugas yang diembankan kepadanya. Manajemen Hotel MMUGM Yogyakarta berusaha sebaik mungkin dalam menciptakan lingkungan kerja yang kondusif dan nyaman bagi karyawannya, seperti penyediaan air conditioning dalam ruangan kerja, menyediakan tempat penyimpanan bagi alatalat kerja karyawan, membuat taman di hotel, adanya Closed Circuit Television (CCTV) dan lain - lain. Isu- isu yang terkait dalam lingkungan kerja di Hotel MMUGM Yogyakarta salah satunya adalah status kepegawaian. Beberapa karyawan hotel masih berstatus kontrak dan percobaan. Anggapan karyawan kontrak atau percobaan cenderung mudah diberhentikan akan mempengaruhi kinerja karyawan. Hal ini harus diperhatikan oleh manajemen khusunya bagian SDM demi terciptanya lingkungan kerja yang nyaman.

Mengingat bahwa setiap karyawan dalam suatu perusahaan berasal dari berbagai latar belakang yang berbeda-beda, maka sangat penting bagi manajemen untuk Yogyakarta. melihat apa kebutuhan dan harapan karyawannya, bakat dan keterampilan yang mereka miliki serta bagaimana rencana karyawan tersebut pada masa mendatang. Dengan pertimbangan tersebut, manajemen SDM dapat menempatkan karyawan pada posisi pekerjaan yang tepat sehingga karyawan menjadi lebih termotivasi dalam melakukan tanggung jawabnya. Menurut Siagian, S.P. (2009) mengemukakan bahwa motivasi sebagai daya pendorong yang mengakibatkan seorang anggota organisasi mau dan rela untuk menggerakkan kemampuannya (dalam bentuk keahlian atau keterampilan) tenaga dan waktunya untuk menyelenggarakan berbagai kegiatan yang menjadi tanggungjawabnya dan menunaikan kewajibannya, dalam rangka pencapaian tujuan dan berbagai sasaran organisasi yang telah ditentukan sebelumnya. Sumber motivasi menurut Zainal et al (2015) menyebutkan ada tiga faktor, yaitu (1) kemungkinan untuk berkembang, (2) jenis pekerjaan, dan (3) apakah mereka dapat merasa bangga menjadi bagian dari perusahaan tempat mereka bekerja. Wujud motivasi kerja yang diberikan manajemen Hotel MMUGM Yogyakarta kepada karyawannya antara lain, memberikan kesempatan promosi kenaikan jabatan, memberikan training terkait bidangnya, adanya pertemuan rutin antar manager dan karyawan, adanya penghargaan dan pengakuan atas kinerja karyawan dan lainlain. Berdasarkan uraian tersebut maka di rumuskan masalah yaitu bagaimanakah pengaruh stres kerja terhadap motivasi kerja, pengaruh lingkungan kerja terhadap motivasi, pengaruh stres kerja terhadap kinerja karyawan, pengaruh lingkungan kerja terhadap kinerja karyawan, pengaruh motivasi kerja terhadap kinerja karyawan, serta apakah motivasi kerja memediasi pengaruh stres kerja terhadap kinerja karyawan dan apakah motivasi kerja memediasi pengaruh lingkungan kerja terhadap kinerja karyawan di Hotel MMUGM 


\section{TINJAUAN LITERATUR}

\section{Stres Kerja}

Menurut Zainal et al (2015), stres kerja adalah suatu kondisi ketegangan yang menciptakan adanya ketidakseimbangan fisik dan psikis, yang mempengaruhi emosi, proses berpikir, dan kondisi seorang karyawan. Stres yang terlalu besar dapat mengancam kemampuan seseorang untuk menghadapi lingkungan. Sebagai hasilnya, pada diri para karyawan berkembang berbagai macam gejala stres yang dapat mengganggu pelaksanaan kerja mereka.

\section{Lingkungan Kerja}

Menurut Sutrisno, E. (2013), lingkungan kerja adalah keseluruhan sarana dan prasarana kerja yang ada di sekitar karyawan yang sedang melakukan pekerjaan yang dapat mempengaruhi pelaksanaan pekerjaan. Lingkungan kerja meliputi tempat bekerja, fasilitas dan alat bantu pekerjaan, kebersihan, pencahayaan, ketenangan, termasuk juga hubungan kerja antara orangorang yang ada ditempat tersebut.

\section{Motivasi Kerja}

Menurut Kadarisman, M. (2012), motivasi kerja adalah penggerak atau pendorong dalam diri seseorang untuk mau berperilaku dan bekerja dengan giat dan baik sesuai dengan tugas dan kewajiban yang telah diberikan kepadanya.

\section{Kinerja karyawan}

Menurut Mangkunegara, A.H. (2011), Kinerja Karyawan (prestasi kerja) adalah hasil kerja secara kualitas dan kuantitas yang dicapai oleh seseorang pegawai dalam melaksanakan tugasnya sesuai dengan tanggung jawab yang diberi kepadanya.

\section{METODE, DATA, DAN ANALISIS}

Penelitian ini bersifat deskriptif kuantitatif, didesain untuk mengetahui pengaruh antara variabel $X$, variabel $Z$ dan variabel $\mathrm{Y}$, diamana variabel $\mathrm{X}$ yaitu stres kerja dan lingkungan kerja sebagai variabel independen, variabel $\mathrm{Z}$ adalah kinerja karyawan yang merupakan variabel dependen, serta variabel Y sebagai motivasi kerja atau variabel yang secara teoretis mempengaruhi hubungan antara variabel independen $(\mathrm{X})$ dengan variabel dependen (Z) menjadi hubungan tidak langsung (Sugiyono, D. 2008). Kemudian akan diuji mengunakan model regresi linear berganda untuk menguji keabsahan data, dan analisis jalur (path analysis), karena peneliti ingin memastikan apakah ada pengaruh antara stres kerja dan lingkungan kerja terhadap kinerja karyawan dengan motivasi kerja sebagai variabel Mediasi.

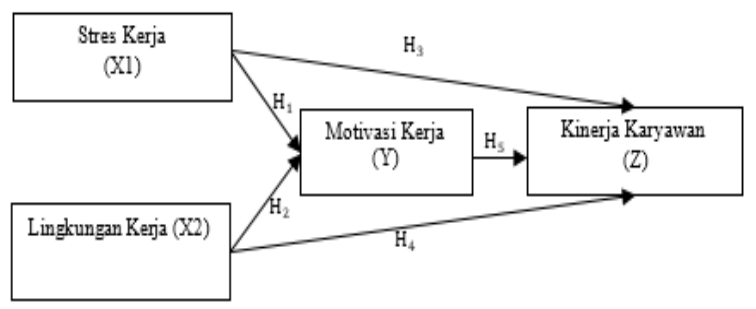

Gambar 1. Desain penelitian.

Sumber: Analisis peneliti, 2020)

Populasi dalam penelitian ini yaitu seluruh karyawan Hotel MMUGM Yogyakarta yaitu sebanyak 85 orang, dengan metode penentuan sampel yaitu sampling jenuh, atau dengan istilah lain disebut sensus, Sampel diambil dengan bantuan kuesioner menggunakan skala ukur rating scale dengan skor 1-4, dimana 1 sangat tidak setuju dan 4 sangat setuju, dimana peneliti tidak berhadapan langsung dengan responden tetapi menggunakan daftar pernyataan. Selain itu juga dilakukan wawancara, observasi, dokumenter dan studi pustaka.

\section{HASIL DAN PEMBAHASAN}

Persamaan linier berganda digunakan untuk mengetahui pengaruh stres kerja dan lingkungan kerja terhadap kinerja karyawan dan dimediasi oleh variabel motivasi kerja. Uji regresi linier berganda dilakukan dengan bantuan program SPSS versi 24 for Windows. 
Berikut disajikan oleh output SPSS pada tabel 4.14 berikut ini:

Tabel 1. Output Regresi Linier Berganda Model 1

\begin{tabular}{|c|c|c|c|c|c|c|c|}
\hline \multirow[b]{2}{*}{ Model } & \multicolumn{2}{|c|}{$\begin{array}{c}\text { Unstandardized } \\
\text { Coefficients }\end{array}$} & \multirow{2}{*}{$\begin{array}{c}\begin{array}{c}\text { Standardized } \\
\text { Coefficients }\end{array} \\
\text { Beta }\end{array}$} & \multirow{2}{*}{$\begin{array}{c}\text { Adjusted R } \\
\text { Square }\end{array}$} & \multirow[b]{2}{*}{$\mathrm{t}$} & \multirow[b]{2}{*}{$\mathrm{F}$} & \multirow[b]{2}{*}{ Sig. } \\
\hline & $\mathrm{B}$ & Std. Error & & & & & \\
\hline 1 (Constant) & 1.718 & 8.033 & & & .214 & & .831 \\
\hline Stres Kerja (X1) & -.022 & .109 & -.016 & .492 & -.197 & 41.630 & .844 \\
\hline Lingkungan Kerja (X2) & 1.845 & .211 & .706 & & 8.760 & & .000 \\
\hline
\end{tabular}

a. Dependent Variable: Motivasi Karyawan (Y)

Sumber: Tabel hasil olah data peneliti, 2020

\section{a. Pengaruh Stres Kerja terhadap Motivasi Kerja \\ Bersasarkan hasil uji regresi ganda} model 1 pada tabel 1 di atas menunjukan bahwa variabel X1 memiliki nilai t hitung 0.016 lebih kecil dari t tabel dengan d.k. $=85$ $(\mathrm{N}-2)$ yaitu 1.989, dengan nilai sig. 0.844 lebih besar dari probabilitas 5\%, artinya bahwa varibael stress kerja X1 tidak berpengaruh positif dan signifikan terhadap variabel motivasi kerja $\mathrm{Y}$, sehingga hipotesis pertama ditolak.

Temuan dari hasil tanggapan responden dalam variabel stres kerja menunjukkan bahwa dimensi job demands memiliki pengaruh yang paling tinggi, dimana mayoritas karyawan merasa tidak terbebani dengan target dan waktu dalam bekerja, juga pekerjaan yang overload sehingga waktu istirahat menjadi berkurang.

\section{b. Pengaruh Lingkungan Kerja terhadap Motivasi Kerja}

Bersasarkan hasil uji regresi ganda model 1 pada tabel 1 di atas menunjukan bahwa variabel X2 memiliki nilai t hitung sebesar 8.760 lebih besar dari t tabel 1.989 dengan sig. 0.000 di bawah $5 \%$, ini menunjukan bahwa variabel lingkungan kerja X2 berpengaruh positif dan signifikan terhadap motivasi kerja $\mathrm{Y}$, artinya hipotesis kedua diterima.

Temuan dari hasil tanggapan responden dalam variabel lingkungan kerja menunjukkan bahwa dimensi lingkungan kerja non fisik memiliki pengaruh yang lebih tinggi, ini menunjukkan hasil yang baik, artinya karyawan merasa termotivasi ketika perusahaan juga memperhatikan kenyamanan lingkungan kerja non fisik seperti adanya asuransi senhingga karyawan merasa diperhatikan oleh perusahaan, hubungan harmonis anatara sesama karyawan dan antara karyawan dan atasan, sehingga terciptanya suasana kekeluargaan di lingkungan kerja, di tambah dengan adanya alunan musik yang merdu juga dapat meningkatkan suasana hati, mengurangi stres dan meningkatkan motivasi.

Tabel 2. Output Regresi Linier Berganda Model 2

\begin{tabular}{|c|c|c|c|c|c|c|c|}
\hline & $\begin{array}{r}\text { Unstai } \\
\text { Coef }\end{array}$ & $\begin{array}{l}\text { adardized } \\
\text { ficients }\end{array}$ & $\begin{array}{l}\text { Standardized } \\
\text { Coefficients }\end{array}$ & Adjusted R & & & \\
\hline Model & B & Std. Error & Beta & Square & $\mathrm{t}$ & $\mathrm{F}$ & Sig. \\
\hline 1 (Constant) & 10.584 & 2.650 & & & 3.994 & & .000 \\
\hline Stres Kerja X1 & -.032 & .036 & -.053 & & -.878 & & .382 \\
\hline Lingkungan Kerja X2 & .596 & .097 & .517 &.$/ 15$ & 6.166 & $1.36 /$ & .000 \\
\hline Motivasi Karyawan Y & .170 & .036 & .387 & & 4.677 & & .000 \\
\hline
\end{tabular}

a. Dependent Variable: Kinerja Karyawan Z

Sumber: Tabel hasil olah data peneltiti, 2020 


\section{c. Pengaruh Stres Kerja terhadap Kinerja Karyawan}

Bersasarkan hasil uji regresi ganda model 2 pada tabel 2 di atas menunjukan bahwa variabel X1 memiliki nilai $t$ hitung 0.878 lebih kecil dari t tabel dengan d.k. $=85$ $(\mathrm{N}-2)$ yaitu 1.989, dengan nilai sig. 0.382 lebih besar dari probabilitas 5\%, artinya bahwa varibael stres kerja X1 tidak berpengaruh positif dan signifikan terhadap variabel kinerja karyawan $\mathrm{Z}$, sehingga hipotesis ketiga ditolak.

Temuan dari hasil tanggapan responden dalam variabel stres kerja menunjukkan bahwa dimensi job demands memiliki pengaruh yang paling tinggi, dimana mayoritas karyawan merasa tidak terbebani dengan target dan waktu dalam bekerja, juga pekerjaan yang overload sehingga waktu istirahat menjadi berkurang.

\section{d. Pengaruh Lingkungan Kerja terhadap Kinerja Karyawan}

Bersasarkan hasil uji regresi ganda model 2 pada tabel 2 di atas menunjukan bahwa variabel lingkungan kerja X2 memiliki nilai t hitung sebesar 6.166 lebih besar dari t tabel 1.989 dengan sig. 0.000 di bawah 5\%, ini berarti bahwa variabel lingkungan kerja $\mathrm{X} 2$ memiliki pengaruh positif dan signifikan terhadap variabel kinerja karyawan Z, artinya hipotesis keempat diterima.

Temuan dari hasil tanggapan responden dalam variabel lingkungan kerja menunjukkan bahwa dimensi lingkungan kerja non fisik memiliki pengaruh yang lebih tinggi, ini menunjukkan hasil yang baik, artinya karyawan merasa termotivasi ketika perusahaan juga memperhatikan kenyamanan lingkungan kerja non fisik seperti adanya asuransi senhingga karyawan merasa diperhatikan oleh perusahaan, hubungan harmonis anatara sesama karyawan dan antara karyawan dan atasan, sehingga terciptanya suasana kekeluargaan di lingkungan kerja, di tambah dengan adanya alunan musik yang merdu juga dapat meningkatkan suasana hati, mengurangi stres dan meningkatkan motivasi.

\section{e. Pengaruh Motivasi Kerja terhadap Kinerja Karyawan}

Bersasarkan hasil uji regresi ganda model 2 pada tabel 2 di atas menunjukan bahwa variabel motivasi $\mathrm{Y}$ memiliki t hitung sebesar 4.677 lebih besar dari t tabel 1.989 dengan nilai sig. 0.000 lebih kecil dari probabilitas 5\%, sehingga variabel motivasi berpengaruh positif dan signifikan terhadap kinerja karyawan Z, artinya hipotesis kelima diterima.

Temuan dari hasil tanggapan responden dalam variabel motivasi kerja menunjukan bahwa kebutuhan sosial memiliki pengaruh yang paling tinggi. Hal ini berarti bahwa manajemen Hotel MMUGM Yogyakarta Yogyakarta mampu memenuhi kebutuhan yang sosial karyawan, seperti mengadakan acara bagi karyawan agar saling mengenal, mampu menciptakan hubungan kerja yang harmonis antar karyawan sehingga mampu bekerja sama dalam team, serta atasan mampu menjaga hubungan yang harmonis dengan bawahannya.

\section{f. Motivasi Kerja Memediasi Pengaruh Stres Kerja terhadap Kinerja Karyawan}

Berdasarkan pada nilai Standardized Coefficients Beta pada gabungan tabel 1 dan tabel 2 dengan perhitungan sebagai berikut:

Stres Kerja X1 $\rightarrow$ Motivasi Kerja Y (P1) = 0.016 , Stres Kerja X1 $\rightarrow$ Kinerja Karyawan Z $(\mathrm{P} 3)=-0.053$, Motivasi Kerja $\mathrm{Y} \rightarrow$ Kinerja Karyawan Z $(\mathrm{P} 5)=0.387$, Nilai perhitungan langsung $(\mathrm{P} 3)=-0.053$, Nilai perhitungan tidak langsung $(\mathrm{P} 1 \mathrm{X} \mathrm{P} 5)=-0.016 \times 0.387=$ $-0.006$

Berdasarkan perhitungan di atas diketahui nilai perhitungan tidak langsung yaitu $-0.006>$ dari nilai perhitungan langsung yaitu -0.053 , sehingga dapat disimpulkan bahwa ada pengaruh positif dan signifikan motivasi kerja memediasi pengaruh stres kerja terhadap kinerja karyawan, artinya bahwa hipotesis keenam diterima.

Hal ini menunjukan bahwa pengaruh negatif antara stres kerja dengan kinerja karyawan jika di mediasi dengan motivasi maka pengaruh tersebut akan berubah 
menjadi pengaruh yang positif. Artinya tingginya stres kerja akan meningkatkan kinerja karyawan kalau dimediasi dengan motivasi kerja. Berikut di sajikan dalam gambar 2. di bawah ini:

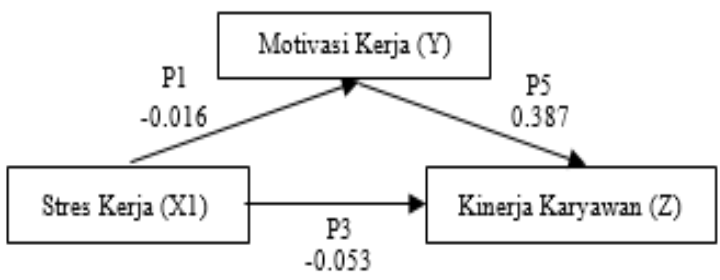

Gambar 2. Koefisien Jalur Pengaruh Stres Kerja terhadap Kinerja Karyawan dengan Motivasi Kerja sebagai Variabel Mediasi.

(Sumber: Analisis dan hasil olah data peneliti, 2020)

\section{g. Motivasi Kerja Memediasi} Pengaruh Lingkungan Kerja terhadap Kinerja Karyawan

Berdasarkan pada nilai Standardized

Coefficients Beta pada gabungan tabel 1 dan tabel 2 dengan perhitungan sebagai berikut:

Lingkungan Kerja X2 $\rightarrow$ Motivasi Kerja $\mathrm{Y}(\mathrm{P} 2)=0.706$, Lingkungan Kerja $\mathrm{X} 2 \rightarrow$ Kinerja Karyawan Z $(\mathrm{P} 4)=0.517$, Motivasi Kerja $\mathrm{Y} \rightarrow$ Kinerja Karyawan Z $(\mathrm{P} 5)=0.387$, Nilai perhitungan langsung $(\mathrm{P} 4)$ $=0.517$, Nilai perhitungan tidak langsung $(\mathrm{P} 2$ $X \mathrm{P} 5)=0.706 \mathrm{X} 0.387=0.273$.

Berdasarkan perhitungan di atas diketahui nilai perhitungan tidak langsung yaitu $0.273<$ dari nilai perhitungan langsung yaitu 0.517, sehingga dapat disimpulkan bahwa tidak ada pengaruh positif dan signifikan motivasi kerja memediasi pengaruh lingkungan kerja terhadap kinerja karyawan, itu artinya bahwa hipotesis ketujuh tidak diterima.

Berdasarkan hasil penelitian di atas, maka dapat dikatakan bahwa lingkungan kerja karyawan, baik fisik maupun non fisik jika diperhatikan oleh manajemen, maka akan meningkatkan kinerja karyawan di Hotel MMUGM Yogyakarta tanpa harus ada Motivasi Kerja. Berikut disajikan dalam gambar 3 di bawah ini:

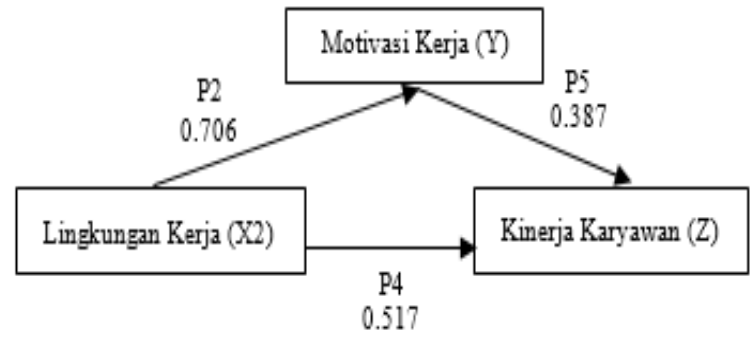

Gambar 3. Koefisien Jalur Pengaruh Lingkungan Kerja terhadap Kinerja Karyawan dengan Motivasi Kerja sebagai Variabel Mediasi.

(Sumber: Analisis dan hasil olah data peneliti,2020)

\section{KESIMPULAN}

Berdasarkan hasil analisis data dan pengujian hipotesis yang telah dilakukan dan dijelaskan sebelumnya, maka dapat ditarik kesimpulan bahwa stres kerja tidak berpengaruh terhadap motivasi dan kinerja karyawan di Hotel MMUGM Yogyakarta, artinya stres kerja karyawan yang tinggi, tidak meningkatkan motivasi dan kinerja karyawan dalam bekerja. Sedangkan Lingkungan kerja karyawan, berpengaruh terhadap motivasi dan kinerja karyawan yang artinya semakin baik lingkungan kerja, maka motivasi dan kinerja kerja karyawan akan meningkat.

Motivasi kerja berpengaruh terhadap kinerja karyawan serta memediasi pengaruh stres kerja terhadapa kinerja karyawan dan tidak memediasi pengaruh lingkungan kerja terhadap kinerja karyawan di Hotel MMUGM Yogyakarta. Artinya bahwa ketika karyawan diberi motivasi dalam bekerja, maka akan berdampak pada meningkatnya kinerja karyawan. Disisi lain, tingginya stres kerja karyawan akan meningkatkan kinerja karyawan, jika di mediasi dengan motivasi kerja yang baik, sedangkan lingkungan kerja baik, akan langsung meningkatkan kinerja karyawan tanpa harus miningkatkan motivasi kerja karyawan terlebih dahulu.

\section{SARAN}

Berdasarkan hasil penelitian, penulis memberikan beberapa saran yaitu hendaknya manajemen khususnya manajer HRF Hotel supaya memperhatikan kinerja karyawan, khususnya hasil pekerjaan. Manajer agar 
lebih mengawasi pekerjaan karyawannya, agar karyawan merasa adanya support dari atasan sehingga karyawan bertanggung jawab dalam melakukan pekerjaannya. Selain itu, tata letak ruang kerja yang kurang strategis akan tidak efektif dan justru menurunkan kualitas lingkungan kerja. Sehingga khususnya bagi General Manager Hotel supaya memperhatikan kondisi ini dengan menyediakan ruang kerja yang strategis bagi karyawannya agar dapat meningkatkan kinerja karyawan.

Selain itu juga, kepada perusahaan khusunya Pimpinan HRF Hotel supaya juga memperhatikan status karyawan kontrak dan karyawan outsourcing. Hal ini perlu diperhatikan oleh perusahaan, agar tidak terjadi konflik antar karyawan yang akan meningkatkan kesenjangan diantara karyawan tetap dan kontrak maupun outsourcing, dengan memberikan motivasi dalam bentuk lain kepada karyawan kontrak maupun outsourcing demi kelancaran kegiatan usahanya. Selain itu, kepada karyawan Hotel agar memperhatikan penggunaan waktu dalam bekerja khususnya dalam memanfaatkan waktu luang untuk belajar sesuatu yang baru untuk menambah keterampilan karyawan tersebut. Atasan bisa menegur atau memberi motivasi agar karyawan bisa menggunakan waktu luang yang ada untuk mempelajari sesuatu yang baru agar kapabilitas karyawan semakin baik.

\section{DAFTAR PUSTAKA}

Afandi, P. 2018. Manajemen Sumber Daya Manusia (Teori, Konsep dan Indikator). Riau: Zanafa Publishing.
Dinas Pariwisata Provinsi D.I Yogyakarta. 2019. Statistik Kepariwisataan 2018. Yogyakarta: Dinas Pariwisata Provinsi D.I Yogyakarta

Kadarisman, M, 2012. Manajemen Pengembangan Sumber Daya Manusia. Jakarta: Rajawali Pers, Jakarta.

Mangkunegara, A.P. 2011. Manajemen Sumber Daya Manusia Perusahaan. Bandung: PT. Remaja Rosdakarya.

Nuraini, T. 2013. Manajemen Sumber Daya Manusia. Pekanbaru: Yayasan Aini Syam

Setyawan, E. B. 2018. Pengaruh Motivasi

Dan Disiplin Terhadap Kinerja Karyawan (Studi Kasus Pada CV. Indobatu Makmur Palembang). Journal of Tourism and Economic, 1(2).

Siagian, S.P. 2009. Manajemen Sumber Daya Manusia, Edisi I, Cetakan Ketiga Belas, Jakarta : Bumi Aksara.

Sugiyono, D. 2008. Metode penelitian bisnis. Bandung: Pusat Bahasa Depdiknas.

Sutrisno, E. 2013. Manajemen Sumber Daya Manusia Edisi pertama. Jakarta: Kencana Prenada Media Group

Yulianto, A. 2019. Pengaruh Jumlah Pengunjung Daya Tari Wisata (DTW) Terhadap Occupancy Hotel Dengan Mderating Variabel Jumlah Kamar Tersedia Di Daerah Istimewa Yogyakarta. Journal of Tourism and Economic, 2(1).

Zainal, V. R., Ramly, H. M., Mutis, T., \& Arafah, W. 2015. Manajemen Sumber Daya Manusia Untuk Perusahaan. Edisi Ketiga. Cetak Ketujuh. Jakarta: Rajawali Pers. 